\title{
Criteria for a Clinically Informative Serum Biomarker in Acute Ischaemic Stroke: A Review of S100B
}

\author{
Pooja Dassan ${ }^{a}$ Geoffrey Keir ${ }^{b}$ Martin M. Brown ${ }^{a}$

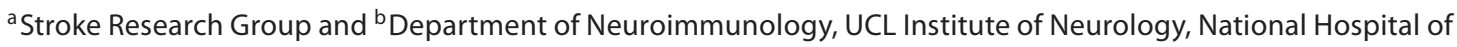 \\ Neurology and Neurosurgery, London, UK
}

Key Words

S100B protein - Biomarker $\cdot$ Acute ischaemic stroke

\begin{abstract}
Background and Purpose: Serum S100B has been widely studied as a biomarker in acute ischaemic stroke. The main objective of this review was to appraise the published literature on S100B and determine its clinical applicability. Methods: Medline was searched to identify studies on S100B (or S-100B) in acute ischaemic stroke. The authors have proposed the criteria for a clinically informative serum biomarker for acute ischaemic stroke, and relevant articles relating to these criteria were then selected. Results: Studies have shown that S100B has a low specificity for acute ischaemic stroke because of its tendency to be raised from extracranial sources. Data regarding S100B kinetics compiled from 6 longitudinal studies show that serum levels are not raised immediately following acute ischaemic stroke and peak 3 days after symptom onset. However, serum S100B levels correlate well with infarct volume and are higher in stroke patients at risk of malignant infarction or haemorrhagic transformation after thrombolysis. In addition, serum S100B levels correlate well with functional outcome. Conclusion: The ev-
\end{abstract}

idence suggests that S100B is not a valuable biomarker for diagnosing acute ischaemic stroke. Instead, it may have a more promising role in non-specialist hospitals, as an additional tool for identifying patients at increased risk of specific early neurological complications after stroke and as a surrogate marker of cerebral damage and functional outcome, particularly in a research setting.

Copyright $\odot 2009$ S. Karger AG, Basel

\section{Introduction}

The National Institute of Health Biomarker Definitions Working Group (1988) defines a biological marker (biomarker) as 'a characteristic that is objectively measured and evaluated as an indicator of normal biological processes, pathogenic processes, or pharmacological responses to a therapeutic intervention' [1]. Considerable effort is currently being spent, identifying useful biomarkers for use in the diagnosis and treatment of acute ischaemic stroke. The current challenges facing stroke physicians, where a serum biomarker may provide additional information to improve management, are: (1) stroke diagnosis; (2) identifying patients at risk of early

\section{KARGER}

Fax +41613061234 E-Mail karger@karger.ch www.karger.com (c) 2009 S. Karger AG, Basel

1015-9770/09/0273-0295\$26.00/0

Accessible online at:

www.karger.com/ced
Dr. Pooja Dassan, Clinical Research Fellow, UCL Institute of Neurology

Box 6, National Hospital of Neurology and Neurosurgery

Queen Square, London WC1N 3BG (UK)

Tel. +44 207837 3611, ext. 4113, Fax +44 2078379632

E-Mail p.dassan@ion.ucl.ac.uk 
neurological complications (e.g. malignant cerebral infarction), and (3) evaluating the severity of brain damage to predict final outcome.

Serum S100B has received most attention in the literature over the last decade and continues to be widely investigated as a biomarker in several different aspects of acute stroke care. However, its utility to clinicians remains uncertain. We reviewed and appraised the published literature on S100B to determine its clinical applicability in acute ischaemic stroke.

\section{Potential Use for Biomarkers}

\section{Acute Stroke Diagnosis}

In order to maximise treatment benefits with recombinant tissue plasminogen activator within the therapeutic window, it is important to make an accurate and early diagnosis of acute ischaemic stroke. In most hospitals, the diagnosis of an acute ischaemic stroke is made solely on clinical grounds after excluding cerebral haemorrhage by brain CT [2]. CT is the most reliable method for demonstrating haemorrhage within the first week after onset [3]. However, the CT scan is normal in about $30 \%$ of acute ischaemic strokes, especially within the first few hours after onset [4]. Other CT modalities have also been shown to be very useful in the acute setting and include CT angiography and CT perfusion. The former provides a rapid and reliable method for imaging the intracranial vasculature. Alternatively, CT perfusion allows clinicians to quantify the cerebral blood flow to the potentially ischaemic area of brain tissue acutely in ischaemic stroke patients. Furthermore, with the advent of newer MR sequences, including diffusion-weighted and perfusion-weighted imaging, it is now possible to identify ischaemic tissue at risk of infarction and therefore better selection of potential candidates for thrombolysis therapy, even beyond the therapeutic window [5]. However, despite the emergence of these new imaging modalities, unfortunately they are still not widely available within an emergency setting. Hence, a diagnostic biomarker of acute cerebral infarction, developed as a rapidresponse testing kit, would have a valuable role in confirming the diagnosis of acute stroke, particularly in diagnostically challenging cases when the CT findings are normal or equivocal.

Substantial progress has already been made in improving stroke recognition, with the development of simple tools designed to help paramedics recognise acute stroke, e.g. the Face Arm Speech Test [6], the use of which has enabled paramedics to achieve a diagnostic accuracy of between 80 and 95\% for acute stroke [7]. Therefore, a valuable diagnostic biomarker for acute stroke would need to achieve a diagnostic sensitivity of $>90 \%$ to be truly useful in the emergency room.

A number of conditions mimic and confound the diagnosis of acute ischaemic stroke. Between 7 and $25 \%$ of patients seen with suspected stroke in the general medical and emergency department settings subsequently turn out to have a non-stroke diagnosis [8, 9]. Examples of common stroke mimics include cerebral tumour, postictal paresis and metabolic disturbances such as hypoglycaemia. Hypoglycaemia and cerebral tumours can be reliably excluded by a bedside blood test and CT imaging, respectively, but other stroke mimics such as postictal paresis cause more diagnostic confusion. As a result, it is often difficult to exclude common stroke mimics, even after clinical evaluation and brain CT.

\section{Identification of Early Neurological Complications}

Between 25 and $35 \%$ of patients who suffer an acute ischaemic stroke experience early neurological complications in the first $48-72 \mathrm{~h}$ [10]. This is associated with worse outcome [11]. Biomarkers could have a role in predicting which patients are at high risk of two potential causes of early deterioration, malignant cerebral oedema and symptomatic haemorrhagic transformation.

Severe brain oedema complicating large middle cerebral artery infarcts can be fatal in cases where transtentorial herniation occurs and early decompressive craniotomy is the life-saving treatment of choice [12]. A biomarker able to identify patients at high risk of developing malignant infarction would facilitate early surgical intervention.

Symptomatic haemorrhagic transformation is an important complication of thrombolysis. Recent MRI-based studies suggest that post-stroke blood-brain barrier dysfunction is an important step in the development of cerebral haemorrhage after thrombolysis therapy [13]. Detection of a biomarker sensitive to blood-brain barrier damage might allow clinicians to avoid thrombolysis in patients who are at an increased risk of cerebral haemorrhage.

\section{Surrogate Marker of Brain Damage and Final \\ Outcome}

It is logical to suppose that the serum level of a biomarker might correlate with the severity of brain damage and could therefore be used as a surrogate marker to monitor the effectiveness of treatment. To validate this 
use, the levels of the biomarker should correlate with infarct size and final outcome. A reliable prediction of prognosis early after onset of stroke would also allow better forward planning, facilitate the selection of suitable treatment strategies and enable the clinician to give accurate information to patients and carers. A number of methods of predicting outcome, including measuring infarct volume, have been developed, but none have proven to be sufficiently good indicators to enter routine practice.

\section{Criteria for an Informative Biomarker for Acute}

Ischaemic Stroke

In order to evaluate the clinical applicability of S100B in acute stroke care, we propose a set of criteria to assess the value of a biomarker in the management of acute ischaemic stroke, based on the above requirements. We propose different criteria for each potential area of use, as follows.

A useful biomarker for acute stroke diagnosis should be:

- sensitive to cerebral infarction, including small-volume infarcts (lacunar infarction) not visible on CT;

- brain specific (ideally specific to cerebral infarction);

- detectable soon after onset of the ictus, ideally within an hour of onset;

- able to distinguish between cerebral infarction and common stroke mimics in the emergency room.

A useful biomarker for the prediction of early neurological complications would either:

- identify patients at high risk of malignant cerebral infarction, or

- identify patients at high risk of haemorrhagic transformation after thrombolysis.

A biomarker useful in estimating the extent of cerebral damage, monitoring treatment response and/or predicting prognosis should have serum levels that:

- correlate with infarct volume;

- correlate with measures of final outcome.

\section{Search Strategy}

A literature search was conducted using Medline (January 1950 to April 2008) to identify articles on S100B in acute ischaemic stroke. The search criteria included the terms S100 or S-100, S100B or S-100B, marker or biomarker and one or more of the following terms: stroke, infarction, cerebral ischaemia, cerebral infarction. All patients with primary intracerebral haemorrhage were excluded, and therefore, if studies did not provide separate results for patients with acute ischaemic stroke, they were excluded. We identified 13 relevant studies in accordance with the objectives of the study, and a further 3 additional studies were identified from the bibliographies of the retrieved articles.

\section{Distribution and Action}

Protein S100B belongs to a large multigenic family of calcium-modulated proteins (S100 proteins). They get their name from the fact that they are soluble in $100 \%$ saturated ammonium sulphate [14]. S100B is found in abundance in the astroglial compartment of the brain, in the Schwann cells of the peripheral nervous system and extraneuronally in melanocytes, adipocytes and chondrocytes [15].

Traditionally, S100B has been considered a reliable marker of astrocytic brain damage. However, a recent study has shown that $\mathrm{S} 100 \mathrm{~B}$ is localised in many cell types in the human brain including astrocytes, oligodendrocytes, choroid plexus epithelium and neurones [16]. It has also been suggested that S100B may be a marker of bloodbrain barrier dysfunction rather than specifically glial damage [17].

\section{S100B and Diagnosis of Cerebral Infarction}

\section{Sensitivity to Cerebral Infarction}

Several studies have reported that serum S100B levels are significantly raised following cerebral infarction [1827]. A summary of the main clinical studies published on S100B in acute ischaemic stroke is given in table 1 . These studies have shown that serum S100B levels are raised within the first 3 days after acute ischaemic stroke onset. Patients with large-artery, cortical infarcts have higher serum S100B levels compared to patients with lacunar infarcts [19-21, 25]. However, it is plausible that these results may be skewed, as the subjects with cortical infarcts in these studies had larger infarct volumes. This makes it difficult to infer the relative contribution of the location and the volume of infarction.

One study reported that patients with transient ischaemic attack or normal CT brain imaging at onset have significantly lower serum S100B levels, with little variation over time, compared to patients with an appreciable neurological deficit and abnormal brain imaging at onset [23]. 
Table 1. Synopsis of the main published clinical studies reporting on serum S100B levels after acute ischaemic stroke

\begin{tabular}{|c|c|c|}
\hline Authors & Number of patients & Main findings \\
\hline $\begin{array}{l}\text { Fassbender } \\
\text { et al. [20], } 1997\end{array}$ & 24 patients with acute ischaemic stroke & $\begin{array}{l}\text { S100B levels significantly raised } 10 \mathrm{~h} \text { after stroke onset; S100B levels } \\
\text { correlate well with volume of infarction and outcome }\end{array}$ \\
\hline $\begin{array}{l}\text { Missler } \\
\text { et al. [22], } 1997\end{array}$ & 44 patients with acute ischaemic stroke & $\begin{array}{l}\text { S100 levels peaked on day } 2.5 \pm 1.3 \text { after infarction; peak values } \\
\text { correlated significantly with infarct volume and outcome }\end{array}$ \\
\hline $\begin{array}{l}\text { Büttner } \\
\text { et al. [21], } 1997\end{array}$ & 26 patients with acute MCA stroke & $\begin{array}{l}\text { S100 levels peaked on days } 2 \text { and } 3 \text { after stroke; S100 levels were } \\
\text { higher in patients with worse neurological deficit but did not } \\
\text { correlate with functional outcome/prognosis }\end{array}$ \\
\hline $\begin{array}{l}\text { Abraha } \\
\text { et al. [19], } 1997\end{array}$ & $\begin{array}{l}68 \text { patients with acute ischaemic stroke, } \\
13 \text { patients with ICH }\end{array}$ & $\begin{array}{l}\text { serum S100 levels are significantly raised in patients with ischaemic } \\
\text { stroke and haemorrhagic stroke; S100 levels are significantly related } \\
\text { to infarct size and clinical outcome }\end{array}$ \\
\hline $\begin{array}{l}\text { Herrmann } \\
\text { et al. [24], } 2000\end{array}$ & $\begin{array}{l}32 \text { patients with acute ischaemic stroke in } \\
\text { the anterior circulation }\end{array}$ & $\begin{array}{l}\text { S100B levels correlated with infarct volume and NIHSS scores on } \\
\text { discharge }\end{array}$ \\
\hline $\begin{array}{l}\text { Elting } \\
\text { et al. [23], } 2000\end{array}$ & $\begin{array}{l}21 \text { patients with acute ischaemic stroke, } \\
10 \text { patients with TBI and } 18 \text { patients with } \\
\text { TIA }\end{array}$ & $\begin{array}{l}\text { S100 levels peaked on day } 3 \text { or } 4 \text { in acute stroke patients, earlier in } \\
\text { the TBI patients and there was minimal variation over time in TIA } \\
\text { patients }\end{array}$ \\
\hline $\begin{array}{l}\text { Foerch } \\
\text { et al. [28], } 2003\end{array}$ & $\begin{array}{l}23 \text { patients with MCA M1 segment } \\
\text { occlusion }(<5 \text { h after stroke onset })\end{array}$ & $\begin{array}{l}\text { single S100B measurement of }<0.4 \mu \mathrm{g} / \mathrm{l} \text { taken } 48-96 \mathrm{~h} \text { after stroke } \\
\text { onset suggested successful clot lysis in this cohort of patients }\end{array}$ \\
\hline $\begin{array}{l}\text { Foerch } \\
\text { et al. [29], } 2004\end{array}$ & $\begin{array}{l}51 \text { patients with proximal MCA occlusion } \\
\text { ( }<6 \mathrm{~h} \text { after symptom onset) }\end{array}$ & $\begin{array}{l}\text { S100B measurements between } 12 \text { and } 24 \mathrm{~h} \text { after stroke onset } \\
\text { predict a malignant course of infarction (specified criteria defined } \\
\text { by authors) with the highest degree of accuracy }\end{array}$ \\
\hline $\begin{array}{l}\text { Wunderlich } \\
\text { et al. [25], } 2004\end{array}$ & 32 patients with acute ischaemic stroke & $\begin{array}{l}\text { patients with main stem or branch occlusion (assessed by repetitive } \\
\text { duplex sonography) have significantly higher S100B levels than } \\
\text { patients with normal flow velocities in basal cerebral arteries }\end{array}$ \\
\hline $\begin{array}{l}\text { Foerch } \\
\text { et al. [26], } 2005\end{array}$ & $\begin{array}{l}39 \text { patients with non-lacunar MCA } \\
\text { infarction presenting }<6 \mathrm{~h} \text { after onset }\end{array}$ & $\begin{array}{l}\text { single } \mathrm{S} 100 \mathrm{~B} \text { measurement at } 48 \text { and } 72 \mathrm{~h} \text { predict final outcome } \\
\text { and infarct volume with the highest accuracy; ideal for future stroke } \\
\text { intervention trials }\end{array}$ \\
\hline $\begin{array}{l}\text { Jauch } \\
\text { et al. [27], } 2006\end{array}$ & $\begin{array}{l}359 \text { patients ( } 178 \text { in the } t-P A \text { treatment } \\
\text { arm and } 181 \text { in the placebo arm) }\end{array}$ & $\begin{array}{l}\text { S100B levels correlate with NIHSS scores and infarct volume; } \\
\text { favourable outcome was associated with smaller changes in S100B } \\
\text { levels in the first } 24 \mathrm{~h}\end{array}$ \\
\hline $\begin{array}{l}\text { Foerch } \\
\text { et al. [30], } 2007\end{array}$ & $\begin{array}{l}275 \text { patients with acute ischaemic stroke } \\
\text { who had received thrombolysis therapy } \\
\text { ( }<6 \text { h after stroke onset) }\end{array}$ & $\begin{array}{l}\text { prethrombolysis S100B levels are an independent risk factor for } \\
\text { haemorrhagic transformation but with low diagnostic accuracy }\end{array}$ \\
\hline
\end{tabular}

MCA = Middle cerebral artery; ICH = intracerebral haemorrhage; NIHSS = National Institutes of Health Stroke Scale; TBI = traumatic brain injury; TIA = transient ischaemic attack; $\mathrm{t}-\mathrm{PA}=$ tissue plasminogen activator.

\section{Brain Specificity}

S100B is not specific to cerebral infarction. Levels are raised in other neuropathologies including traumatic brain injury [31]. In addition, S100B can be released from extracranial malignancies including schwannoma, melanoma and neuroblastoma $[15,32]$.

\section{Detectability Soon after Onset}

Evaluation of the temporal profile of S100B release after acute ischaemic stroke has shown that serum levels are not raised immediately after the ictus [20-25].

We have extracted serum S100B measurements over time from 6 longitudinal studies. Figure 1 shows the mean S100B level at each time point. The compiled data show that there is a gradual increase in levels starting at 8-10 h after symptom onset, followed by a peak at $72 \mathrm{~h}$ 
and then a subsequent drop in levels at $96 \mathrm{~h}$. One longitudinal study found that even patients with a large infarct volume of $>5 \mathrm{~cm}^{3}$ on initial CT did not have increased S100B levels until $10 \mathrm{~h}$ after the ictus [20].

\section{Differentiation from Stroke Mimics}

We were unable to find any studies which have compared S100B as an independent marker, rather than as part of a panel, between patients with acute ischaemic stroke and stroke mimics.

\section{Use of S100B in a Panel}

Attempts have been made to improve the diagnostic utility of S100B levels by including S100B as part of a panel of markers in order to improve the sensitivity of diagnosing acute stroke. In one study, the markers included in the panel were: S100B; B-type neurotrophic growth factor; von Willebrand factor; matrix metalloproteinase 9, and monocyte chemotactic protein 1 [33]. The authors concluded that the panel of all 5 markers provided a higher diagnostic sensitivity (91.7\%) and specificity (93\%) for diagnosing acute ischaemic stroke for samples taken within $6 \mathrm{~h}$, as compared to using any of the markers individually. A second study investigated a panel of markers made up of: S100B, matrix metalloproteinase 9, vascular cell adhesion molecule and von Willebrand factor [34]. The authors claimed a sensitivity and specificity of $90 \%$ for predicting stroke using this panel. However, despite quoting fairly high sensitivities and specificities in both these studies, one major limitation is that the majority of the control population in both these studies were age-matched subjects without neurological symptoms. However, Laskowitz et al. [35] studied a panel of 5 biomarkers, including brain natriuretic peptide, C-reactive protein, D-dimer, matrix metalloproteinase 9 and S100B in patients with suspected acute stroke (including stroke mimics). These authors reported a much lower level of sensitivity (81\%) and specificity (70\%) for predicting acute ischaemic stroke than the previous 2 studies.

\section{S100B and Prediction of Early Neurological Complications}

One study has shown that a single S100B measurement of $>1.03 \mu \mathrm{g} / \mathrm{l}$ taken at $24 \mathrm{~h}$ after onset of stroke provided a fairly high sensitivity (94\%) and specificity (83\%) for predicting malignant infarction in patients with proximal middle cerebral artery occlusion [29]. In this study,

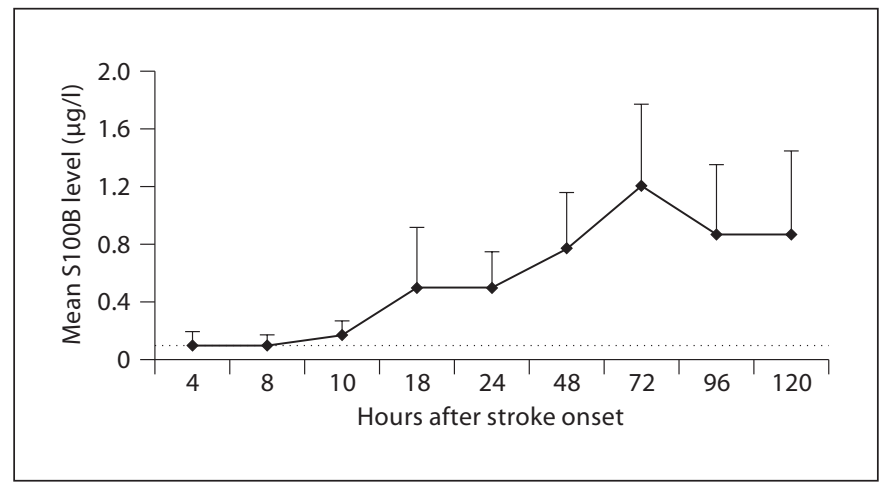

Fig. 1. Temporal profile of serum S100B release after acute ischaemic stroke. The dashed line corresponds to the normal level in healthy subjects (data compiled from 6 longitudinal studies).

16 patients out of a total of 51 developed malignant infarction.

Another recent study reported that median prethrombolysis serum S100B levels were higher in patients who later incurred haemorrhagic transformation (symptomatic or asymptomatic) after thrombolysis therapy than those without haemorrhage ( 0.14 vs. $0.11 \mu \mathrm{g} / \mathrm{l} ; \mathrm{p}=0.017$ ) [30]. They reported that a pretreatment S100B level of $>0.23 \mu \mathrm{g} / \mathrm{l}$ (the median S100B level in healthy individuals was $0.06 \mu \mathrm{g} / \mathrm{l}$ ) had a sensitivity and specificity for predicting severe parenchymal haemorrhage of 46 and $82 \%$, respectively.

\section{S100B and Estimating the Extent of Cerebral Damage, Monitoring Treatment Response and/or Predicting Outcome}

Several studies have shown that serum S100B levels measured in samples taken more than $24 \mathrm{~h}$ after stroke onset demonstrate a strong correlation with the degree of neurological deficit and the final infarct volume $[19,20$, $22,25,26,29,30]$. However, S100B measurements taken within $2 \mathrm{~h}$ of stroke onset do not correlate with National Institute of Health Stroke Scale scores at onset, early ischaemic changes on CT brain or with the infarct volume [27].

S100B has also been proposed as a surrogate marker for successful clot lysis in patients with proximal middle cerebral artery occlusion who had received intravenous thrombolysis. One study reported that a single S100B measurement of $<0.4 \mu \mathrm{g} / \mathrm{l}$ obtained $48-96 \mathrm{~h}$ after stroke onset indicates early ( $<6 \mathrm{~h})$ reperfusion [28]. Moreover, 
final infarct volumes, measured on day 7 after stroke onset, were significantly smaller in patients with early recanalisation and larger in patients without recanalisation $(p<0.001)$. Therefore, these results appear to emphasise the strong correlation between serum S100B levels and final infarct volume as opposed to characterising S100B as an independent marker of vessel recanalisation.

S100B may have a role as a predictor of functional outcome [19-21, 24-27]. The majority of these studies examined S100B concentrations against different functional outcome scales including: Barthel Index, modified Rankin Score and Glasgow Outcome Score. Wunderlich et al. [25] found that a 48 -hour S100B concentration over $0.2 \mu \mathrm{g} / \mathrm{l}$ in patients with acute infarction was a strong predictor of a poor functional outcome (sensitivity $85 \%$, specificity 92\%). Jauch et al. [27] observed worse outcomes at the 3-month follow-up in patients with faster rates of change in $\mathrm{S} 100 \mathrm{~B}$ concentrations over the first $24 \mathrm{~h}$ after stroke onset. Fassbender et al. [20] reported that neurological outcome was associated with serum S100 levels, but the only outcome measure used in this study was the Scandinavian Stroke Scale, a tool used to score neurological deficit and not outcome. Foerch et al. [26] reported that a 48 -hour serum S100B level of $\leq 0.37 \mu \mathrm{g} / \mathrm{l}$ predicted an independent outcome (sensitivity $87 \%$, specificity $78 \%$ ). These latter authors demonstrated that S100B predicts outcome after acute stroke, independently of several variables including age, lesion side, National Institutes of Health Stroke Scale score, vascular risk factors and stroke aetiology. However, none of these studies evaluated whether S100B predicts clinical outcome independently of the final infarct volume, a variable that has been shown to significantly correlate with serum S100B levels [18-24].

\section{Discussion}

S100B continues to be widely studied as a biomarker for acute ischaemic stroke. In this article, we have proposed a number of criteria for assessing the utility of a biomarker in the management of stroke and used these to evaluate S100B.

Our review suggests that $\mathrm{S} 100 \mathrm{~B}$ is not a valuable biomarker for diagnosing acute ischaemic stroke because of its low specificity and delayed kinetics. In addition, we were unable to identify any studies that have directly compared serum S100B levels as an independent biomarker, between patients with acute cerebral infarction and stroke mimics. When included as part of a panel in the assessment of suspected strokes, including stroke mimics, the panel had too low a sensitivity and specificity to be useful in clinical practice. The compiled data from 6 longitudinal studies convincingly show a delayed peak in post-stroke S100B levels. This is in accordance with the current understanding of ischaemic brain injury, where only a small number of cells are subject to immediate necrosis and the remainder, for example those in the penumbral area, undergo a complex process leading to delayed death if perfusion is not restored [36]. However, for S100B to be a useful diagnostic biomarker for the selection of patients for thrombolysis in the emergency room, serum levels should be significantly raised within an hour of stroke onset even in patients who have normal CT brain imaging initially. In light of the temporal profile of serum S100B release, it is unlikely to prove to be a valuable tool for differentiating between ischaemic strokes and stroke mimics in the emergency room.

There is convincing evidence from a number of studies that S100B levels, measured beyond $24 \mathrm{~h}$ after stroke onset, correlate well with the final infarct volume [18-24]. It is hypothesised that $\mathrm{S} 100 \mathrm{~B}$ is released passively from necrotic astroglial cells after cerebral infarction. The main evidence for this comes from the finding that the ischaemic brain tissue, which survives after early vessel recanalisation, subsequently leading to a smaller final infarct volume, does not release S100B into the serum [28].

Studies have demonstrated that S100B measurements may be useful in identifying patients at increased risk of early neurological complications, e.g. malignant cerebral oedema or haemorrhage after thrombolysis. For both these post-stroke complications, infarct volume measurements on diffusion-weighted imaging have previously been shown to be a sensitive method for predicting which patients are at increased risk of these adverse events $[37,38]$. In particular, Oppenheim et al. [37] reported that on diffusion-weighted imaging an infarct volume of $>145$ $\mathrm{cm}^{3}$ predicts patients at high risk of malignant cerebral oedema (sensitivity $100 \%$, specificity $94 \%$ ). Therefore, in specialist hospitals where stroke clinicians have immediate access to multimodal MRI, S100B measurements are unlikely to be helpful in identifying these patients.

Studies have also shown that S100B is a surrogate marker of functional outcome [19-21, 24-27]. However, accurate prediction of functional outcome after ischaemic stroke is difficult because of the significant heterogeneity of stroke. Even so, numerous predictors of functional outcome have been proposed and for any given patient there are several possible variables, with complex 
interactions, which can contribute towards the patient's functional outcome [39]. Several groups have tried to construct complex statistical models to predict outcome in acute stroke patients [40]. Despite this, no adequate model exists. Therefore, it is likely that S100B or any other biomarker for acute stroke will serve at best as an additional variable, amongst several others, capable of predicting functional outcome. However, it may have a more promising role in the research setting, as a surrogate marker in interventional stroke trials as an easily accessible and inexpensive outcome measure.

In conclusion, the evidence suggests that $\mathrm{S} 100 \mathrm{~B}$ is not a valuable biomarker for diagnosing acute ischaemic stroke. The main hurdles governing its use in the emergency room are its delayed kinetics and secondly its low specificity for cerebral infarction. However, serum S100B measurements beyond $24 \mathrm{~h}$ after stroke onset significant- ly correlate with final infarct volume, and in non-specialist hospitals it may have a more promising role, as an additional tool to help clinicians identify patients at high risk of specific early neurological complications. S100B levels correlate with functional outcome and may prove to be a useful and easy-to-perform outcome measure in stroke trials. Conversely, in specialist hospitals where patients are managed exclusively by stroke specialists and have immediate access to multimodal MRI, it is difficult to see how measuring S100B levels will provide any additional information in the management of acute stroke patients.

\section{Acknowledgement}

M.M.B.'s Chair is supported by the Rita Lila Weston Trust for Medical Research.

\section{References}

- 1 Biomarkers Definitions Working Group: Biomarkers and surrogate endpoints: preferred definitions and conceptual framework. Clin Pharmacol Ther 2001;69:89.

$\checkmark 2$ Kidwell CS, Chalela JA, Saver JL, et al: Comparison of MRI and CT for detection of acute intracerebral hemorrhage. JAMA 2004;292: 1823-1830.

3 Jager HR: Diagnosis of stroke with advanced CT and MR imaging. Br Med Bull 2000;56: 318-333.

4 Wardlaw JM, Lewis SC, Dennis MS, et al: Is visible infarction on computed tomography associated with an adverse prognosis in acute ischemic stroke? Stroke 1998;29:1315-1319.

5 Davis SM, Donnan GA, Butcher KS, Parsons M: Selection of thrombolytic therapy beyond $3 \mathrm{~h}$ using magnetic resonance imaging. Curr Opin Neurol 2005; 18:47-52.

-6 Harbison J, Massey A, Barnett L, et al: Rapid ambulance protocol for acute stroke. Lancet 1999;353:1935.

7 Harbison J, Hossain O, Jenkinson D, et al: Diagnostic accuracy of stroke referrals from primary care, emergency room physicians, and ambulance staff using the face arm speech test. Stroke 2003;34:71-76.

$\checkmark 8$ Scott PA, Silbergleit R: Misdiagnosis of stroke in tissue plasminogen activator-treated patients: characteristics and outcomes. Ann Emerg Med 2003;42:611-618.

$\checkmark 9$ Hemmen TM, Meyer BC, Hayes KA, et al: Identification of 'stroke-mimics' among 411 code strokes at the UCSD Stroke Center from September 1998 to March 2001. Stroke 2002; 33:385.

Serum Biomarker in Acute Ischaemic

Stroke
10 Davalos A, Toni D, Iweins F, et al: Neurological deterioration in acute ischemic stroke potential predictors and associated factors in the European Cooperative Acute Stroke Study (ECASS) I. Stroke 1999;30:26312636

11 Toni D, Fiorelli M, Gentile M, et al: Progressing neurological deficit secondary to acute ischemic stroke - a study on predictability, pathogenesis, and prognosis. Arch Neurol 1995;52:670-675.

12 Vahedi K, Hofmeijer J, Juettler E, et al: Early decompressive surgery in malignant infarction of the middle cerebral artery: a pooled analysis of three randomised controlled trials. Lancet Neurol 2007;6:215-222.

13 Hjort N, Wu O, Ashkanian M, et al: MRI detection of early blood-brain barrier disruption - parenchymal enhancement predicts focal hemorrhagic transformation after thrombolysis. Stroke 2008;39:1025-1028.

14 Moore BW: A soluble protein characteristic of the nervous system. Biochem Biophys Res Commun 1965;19:739-744.

15 Donato R: S100: a multigenic family of calcium-modulated proteins of the EF-hand type with intracellular and extracellular functional roles. Int J Biochem Cell Biol 2001;33:637-668.

$>16$ Steiner J, Bernstein HG, Bielau H, Berndt A, Brisch R, Mawrin C, Keilhoff G, Bogerts B: Evidence for a wide extra-astrocytic distribution of S100B in human brain. BMC Neurosci 2007;8:2.

17 Kapural M, Krizanac-Bengez L, Barnett G, et al: Serum S-100 beta as a possible marker of blood-brain barrier disruption. Brain Res 2002;940:102-104.
-18 Persson L, Hardemark HG, Gustafsson J, et al: S-100 protein and neuron-specific enolase in cerebrospinal-fluid and serum - markers of cell-damage in human central-nervoussystem. Stroke 1987;18:911-918.

$\checkmark 19$ Abraha HD, Butterworth RJ, Bath PMW, et al: Serum S-100 protein, relationship to clinical outcome in acute stroke. Ann Clin Biochem 1997;34:366-370.

20 Fassbender K, Schmidt R, Schreiner A, et al: Leakage of brain-originated proteins in peripheral blood: temporal profile and diagnostic value in early ischemic stroke. J Neurol Sci 1997;148:101-105.

21 Buttner T, Weyers S, Postert T, et al: S-100 protein: serum marker of focal brain damage after ischemic territorial MCA infarction. Stroke 1997;28:1961-1965.

22 Missler U, Wiesmann M, Friedrich C, et al: S-100 protein and neuron-specific enolase concentrations in blood as indicators of infarction volume and prognosis in acute ischemic stroke. Stroke 1997;28:1956-1960.

$>23$ Elting JW, de Jager AEJ, Teelken AW, et al: Comparison of serum S-100 protein levels following stroke and traumatic brain injury. J Neurol Sci 2000;181:104-110.

$>24$ Herrmann M, Vos P, Wunderlich MT, et al: Release of glial tissue-specific proteins after acute stroke - a comparative analysis of serum concentrations of protein S-100B and glial fibrillary acidic protein. Stroke 2000;31: 2670-2677. 
25 Wunderlich MT, Wallesch CW, Goertler M: Release of neurobiochemical markers of brain damage is related to the neurovascular status on admission and the site of arterial occlusion in acute ischemic stroke. J Neurol Sci 2004;227:49-53.

-26 Foerch C, Singer OC, Neumann-Haefelin T, et al: Evaluation of serum S100B as a surrogate marker for long-term outcome and infarct volume in acute middle cerebral artery infarction. Arch Neurol 2005;62:1130-1134.

27 Jauch EC, Lindsell C, Broderick J, et al: Association of serial biochemical markers with acute ischemic stroke - the National Institute of Neurological Disorders and Stroke Recombinant Tissue Plasminogen Activator Stroke Study. Stroke 2006;37:2508-2513.

28 Foerch C, de Rochemont RD, Singer O, et al: S100B as a surrogate marker for successful clot lysis in hyperacute middle cerebral artery occlusion. J Neurol Neurosurg Psychiatry 2003;74:322-325.
29 Foerch C, Otto B, Singer OC, et al: Serum S100B predicts a malignant course of infarction in patients with acute middle cerebral artery occlusion. Stroke 2004;35:2160-2164.

30 Foerch C, Wunderlich MT, Dvorak F, et al: Elevated serum S100B levels indicate a higher risk of hemorrhagic transformation after thrombolytic therapy in acute stroke. Stroke 2007;38:2491-2495.

31 Raabe A, Menon DK, Gupta S, et al: Jugular venous and arterial concentrations of serum S-100B protein in patients with severe head injury: a pilot study. J Neurol Neurosurg Psychiatry 1998;65:930-932.

32 Ishiguro Y, Kato K, Ito T, Nagaya M: Determination of 3 enolase isozymes and S-100 protein in various tumors in children. Cancer Res 1983;43:6080-6084.

$>33$ Reynolds MA, Kirchick HJ, Dahlen JR, et al: Early biomarkers of stroke. Clin Chem 2003; 49:1733-1739.

34 Lynch JR, Blessing R, White WD, et al: Novel diagnostic test for acute stroke. Stroke 2004;35:57-63.

>35 Laskowitz DT, Blessing R, Floyd J, White WD, Lynch JR: Panel of biomarkers predicts stroke. Ann NY Acad Sci 2005;1053:30.
36 Pulsinelli WA, Brierley JB, Plum F: Temporal profile of neuronal damage in a model of transient forebrain ischemia. Ann Neurol 1982;11:491-498.

37 Oppenheim C, Samson Y, Manai R, et al: Prediction of malignant middle cerebral artery infarction by diffusion-weighted imaging. Stroke 2000;31:2175-2181.

>38 Mayer TE, Schulte-Altedorneburg G, et al: Serial CT and MRI of ischaemic cerebral infarcts: frequency and clinical impact of haemorrhagic transformation. Neuroradiology 2000;42:233-239.

39 Weimar C, Ziegler A, Konig IR, et al: Predicting functional outcome and survival after acute ischemic stroke. J Neurol 2002;249: 888-895.

40 Counsell C, Dennis M, McDowall M: Predicting functional outcome in acute stroke: comparison of a simple six variable model with other predictive systems and informal clinical prediction. J Neurol Neurosurg Psychiatry 2004;75:401-405. 